\title{
Integration of digital games and remote laboratories with real-time visualization: Conception, Implementation and Evaluation
}

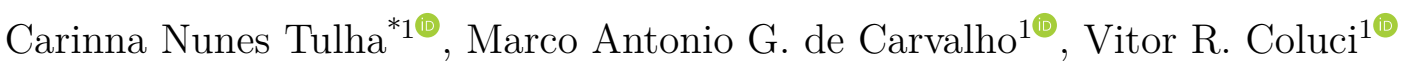 \\ ${ }^{1}$ Universidade Estadual de Campinas, Faculdade de Tecnologia, Limeira, SP, Brasil.
}

Received on May 31, 2021. Revised on July 21, 2021. Accepted on July 24, 2021.

\begin{abstract}
Digital games and remote laboratories are currently technologies to support learning. Different strategies to integrate them have been proposed to improve students' experience and learning during class activities. In this work, we designed, implemented, and evaluated a digital game that provides real-time visualization and manipulation of a remote experiment. The game so-called Fotovolt was applied to teenagers during a class activity about the photovoltaic effect. Facilitated use of the remote experiment, motivation to learn, collaborative work, and concepts recalling were the observed benefits of the proposed integration. However, to obtain effective integrated games with real-time visualization of remote experiments, planned and exclusive access to the remote experiments should be considered. The results show that the students approved the game usability, as well as had their perception of learning increased.
\end{abstract}

Keywords: Remote experiment, digital-game based learning, validation, photovoltaic effect.

\section{Introduction}

Real experiments that can be manipulated through online platforms - remote labs [1, 2] - are important tools to support science learning. In such experiments, users can interact with real equipment remotely and see real-time results through live video streaming. This technology overcomes time and geographic barriers 3 and encourages collaborative work to create projects and to analyze and evaluate data 4. Similarly, digital games also appear as useful tools to motivate students and stimulate students' cooperation, competitiveness, and active learning with immediate feedback [5]. Differently of remote labs, many digital games can be played without external hardware, in personal desktop computers and smartphones. These technologies are especially interesting in times of social distancing, quarantine, and isolation due to the Covid-19 pandemic.

By integrating the characteristics of remote labs and digital games, new forms of learning can be created and have been explored. Few works have studied the concepts behind this integration [6 9] whereas others have already evaluated the integration in class [10 14. For instance, Circuit Warz is a serious game with a virtual world interface and a remote experiment to teach electrical circuits [15]. The user practices parallel/series resistances during exercises and should calculate the correct value of the resistor as fast as they can. Initial tests were performed focusing on user acceptance of the game structure. The results presented indicate that the

\footnotetext{
${ }^{*}$ Correspondence email address: c193014@dac.unicamp.br
}

student enjoyed the project, the collaborative aspect, the interaction and visualization of a circuit.

The visualization of the remote experiment is one important aspect of remote labs since it brings reality to the student's experience, differing from virtual experiments and simulations where artificial scenarios are used. Some works have been used real-time visualization of remote experiments in games. For instance, Antonio et al. has developed a Virtual 3D World game integrated with a remote experiment designed to teach circuit associations (series, parallel and mixed associations) [16] and kingdom Plantae [17. Data from 46 public school students (11-12 years old) that have played the game integrated with a remote microscope [17] considered the game motivated them to learn Science [18.

In this work, we designed, implemented, and evaluated a digital game integrated into a remote lab that allows students to see and interact with the experiment from webcam streaming. The game so-called Fotovolt was designed to support the learning of the photovoltaic effect - the production of an electrical current in a semiconductor by exposing it to light. The Fotovolt evaluation was accomplished through an adapted model used in the educational game area which allowed us to observe aspects such as usability, motivation, and learning perception.

The photovoltaic effect was first created and analyzed in 1839 by Edmund Becquerel. The process consists of the conduction of electrical current by exposing a semiconductor material to light [19]. The photovoltaic cell is formed by a pair of electrodes, in this process one of the electrodes is illuminated. The photovoltaic effect is 
the principle of the photovoltaic cell and essential to the generation of light energy. In Brazil, the basic concepts of the photovoltaic effect are introduced during high school education. The Brazilian National High School Education Guideline [20] recommends the study of ways of producing clean energy.

The paper is organized as follows. Section 2 details the remote lab used in this work. Section 3 describes the design and implementation of the Fotovolt. The method to evaluate the Fotovolt is presented in Section 4 . The results and conclusions are presented in Sections 4 and 5 respectively.

\section{Remote Labs and Digital Games}

There are numerous tools that support the teaching of physics, including digital games. Digital games are playful tools that can provide educational support. The balance of playful and didactic characteristics makes possible activities based on the problem-solving model. To the effective development and use of educational games, strategies were created, for instance, the Digital Game-Based Learning - DGBL. The DGBL was proposed by Prensky in 2001, focusing on the students' motivation. This strategy aims the incentive of students' cooperation, competitiveness, and active learning [5]. According to Prensky, educational games can provide practical learning, activities based on goals and contextualized and immediate feedback.

In 2011, a theoretical research about the integration process of remote laboratories and digital games was performed [7. This work discusses the use of a game-based learning model to increase the game characteristics into an educational environment. According to the authors, during the integration of a remote experiment into a game environment an educational approach must be determined considering: pedagogical strategy, task, map learning and game design. The interface must provide the remote experiment elements and the virtual game environment. We can also conclude the importance of balancing elements of the game with the knowledge skills in the challenges to encourage student motivation.

Students' motivation and learning have been improved using a game integrated with a remote lab to study the control loop problem [10, 11. In this case, the remote experiment is seen by a webcam and the gamification occurs externally, through a competition among groups of students. In these works, the integration is either by directly accessing the remote lab hardware or by gamifying the online platform which the remote lab is accessed. Using a remote experiment, students were exposed to a Proportional and Integral (PI) control loop problem controlled a tank of water through a voltage, connected to a water reservoir. The students were divided into two groups, each team has to protect their tank, trying to keep it stable at the setpoint and attack the other team's tank, causing oscillations. The game was validated at Chemical Process Dynamics and Control class at an American University. The results indicate that $83,3 \%$ of the students believe the game helped with the learning process and enjoyed playing the game. Half of the students felt more motivated after playing the game.

\section{Design and Implementation}

\subsection{Remote laboratory}

Firstly, we have searched for available remote labs related to the photovoltaic effect with free access and open-access code. Our choice was the "Conversion of Light Energy into Electrical Energy" experiment, illustrated in Fig. 1 developed by the Remote Experimentation Laboratory (RExLab) 21. RExLab has developed remote experiments for Engineering, Physics, Chemistry, and Biology and has been awarded the Global Online Laboratory Consortium Award 2017 for the best remotely controlled laboratory. This remote lab is available at the RELLE platform and is set up at the Federal University of Santa Catarina/Brazil.

\section{Conversão de energia luminosa em energia elétrica}
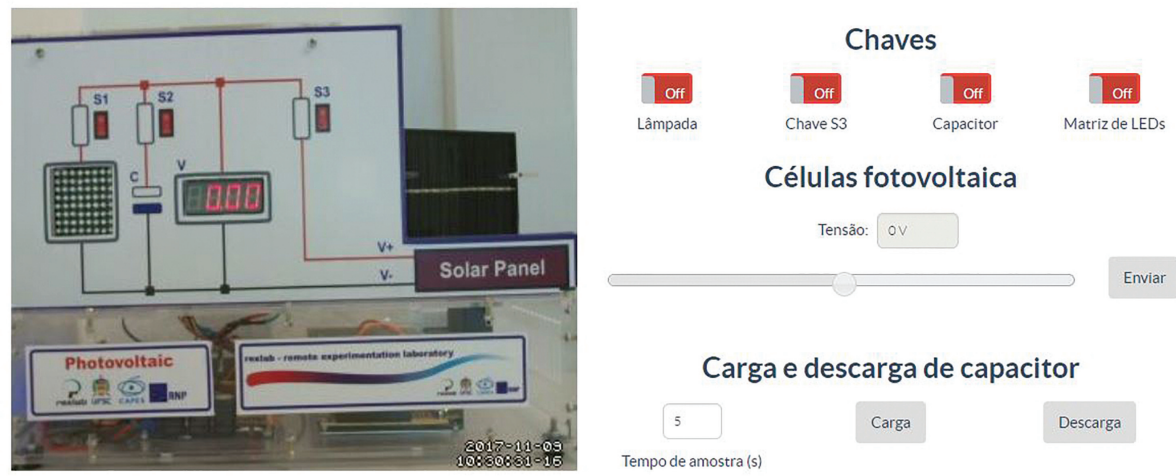

Figure 1: "Conversion of Light Energy into Electrical Energy" experiment. 
The interface of this remote lab is divided into two main parts: a live webcam of the experiment and a set of command keys. Through these keys, the user can turn on/off a lamp, change the incident angle of the light emitted by an array of light-emitting diodes (LED) onto a photovoltaic cell, and control the charge and discharge of a capacitor that saves the energy generated by the cell. To ensure exclusive access to the experiment, the users enter a queue and, once selected, they can interact with the experiment during a maximum time of eight minutes.

\subsection{Digital game}

Having chosen the remote experiment, we have designed and implemented the Fotovolt, an adventure escape game that works with concepts of the photovoltaic effect. In Brazil, this effect is usually taught in the second year of high school, so the target audience is teenagers between 15 and 16 years old. Currently, the Fotovolt has Brazilian Portuguese and Spanish versions.

After seeing the opening scene (Fig. 2), the students need to go through six levels to escape and win the game (Fig. 3). The first five levels involve basic concepts of the photovoltaic effect: (1) light, (2) electricity, (3) conductive materials, (4) energy conversion, and (5) voltage, respectively. The last level involves interaction with the remote experiment. Being an escape game, the main goal is to solve challenges in order to escape rooms (Table 1). The game flows continuously so the return to previous rooms is forbidden. In a bi-dimensional scenario, the students should point out and click objects with the mouse in order to interact with the game. In the last level, when the remote experiment appears, the students interact with it through the command keys. Only a part of the remote experiment appears to the students while the other parts are strategically hidden. The control of the LED array occurs via the interaction with the game mechanisms. To keep the student's attention while the experiment is being used by another student, a standby scene is opened and the student plays with a puzzle of objects that appear during the game.

Game elements such as theme and flow of actions were created with Unity 22. (free version 5.5.0) and the bidimensional graphical design with the Adobe Photoshop CC 23]. Developed in C\#, the game currently only runs on desktops with the Windows operational system. The proposed game Fotovolt is available on GitHub 24]. We have plans to develop a web-based game using the design capabilities of Unity.

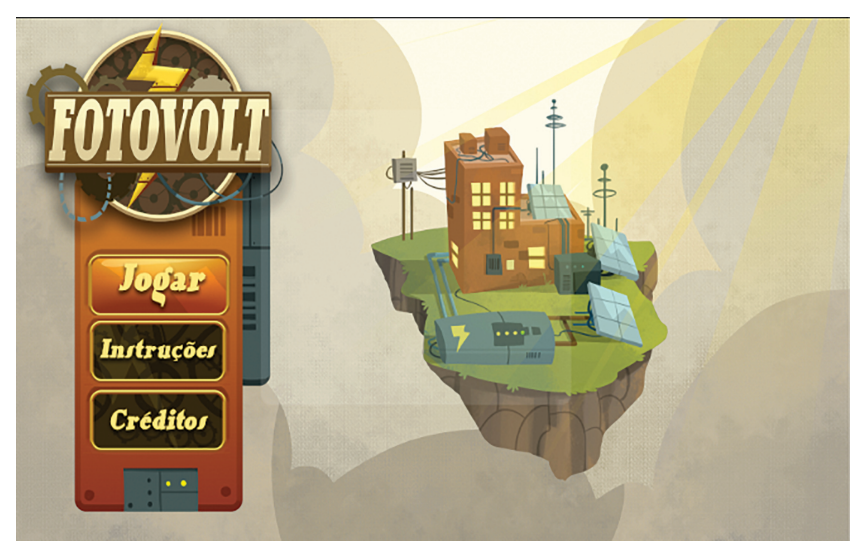

Figure 2: Fotovolt opening scene. The students have to solve challenges in order to escape rooms and win the game. In the opening scene, objects such as photovoltaic plates and electrical cables can be seen outside a building where the rooms are located. The buttons to start the game, to obtain the playing instructions, and to see information of the developers appear on the left.
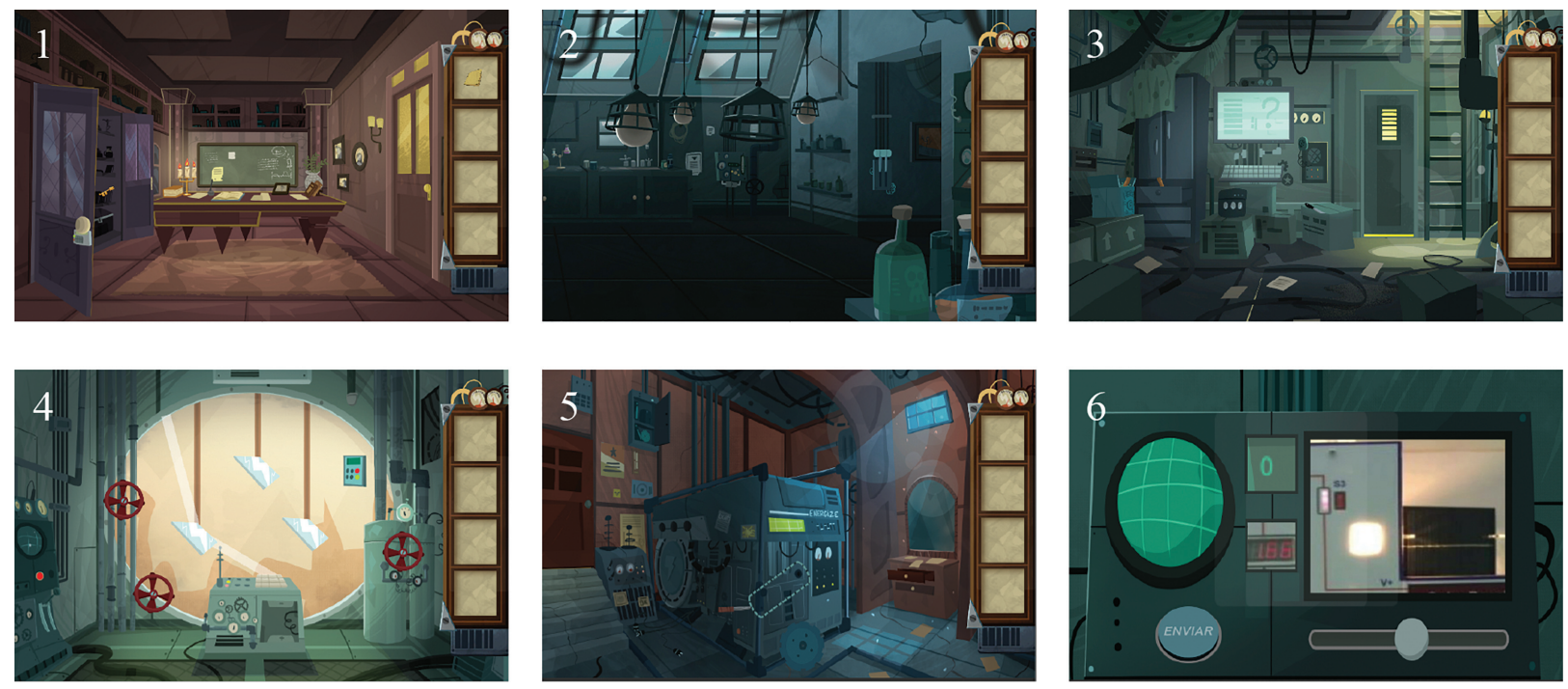

Figure 3: Snapshots of the Fotovolt scenes (1-6, see Table 1). The image from a webcam of the remote experiment can be seen in scene 6 . 
Table 1: Level and related challenges in Fotovolt.

\begin{tabular}{llc}
\hline Level & \multicolumn{1}{c}{ Challenges } & Learning Concept \\
\hline 1 & $\begin{array}{l}\text { Collect a paper and put it in front of a candle at the table to see through the light. } \\
\text { The paper has a series of numbers that can be used to unlock a locker and release a } \\
\text { key to open the door. }\end{array}$ & Light propagation \\
2 & $\begin{array}{l}\text { Slide interlocked tiles in a grid to form the image of a closed electric circuit and } \\
\text { release a lamp. The lamp is used to build a light fixture and to turn on an electrical } \\
\text { circuit and open to a trapdoor. }\end{array}$ & Electric circuits \\
& $\begin{array}{l}\text { An electric box provides the remaining information that should be discovered by } \\
\text { using the resistance equation, available in a paper. The objects must be put in } \\
\text { order in the electric box according to the result of the equation. }\end{array}$ & Conductive materials \\
& $\begin{array}{l}\text { Gears are arranged in the scenario and must be placed in the correct location at a } \\
\text { power generator. To turn on the power generator and open the door, a logic puzzle } \\
\text { game with a labyrinth has to be solved. }\end{array}$ & Energy conversion \\
& $\begin{array}{l}\text { Manipulate cranks are used to move solar boards to capture sun's rays, reach the } \\
\text { expected target, and release enough power to turn on a computer. } \\
\text { In a one-minute period, find out the optimum orientation of the array of LEDs to } \\
\text { maximize energy generation }\end{array}$ & Voltage and geometry \\
& Photovoltaic effect \\
\hline
\end{tabular}

The Websocket 25] protocol was used to provide the connection between the digital game and the remote laboratory, by importing the Socket.io library for Node.JS and the SocketIO package for Unity. When a user tries to connect, a token is generated which indicates the user position in the accessing queue to the remote experiment. Once the remote experiment is available for the user, a Websocket authorization is sent to authorize the manipulation of the game keys and the transmission of commands to the remote experiment. Data exchanged between the remote experiment and the game are converted with the JSONObject class for Unity. A direct connection to the remote lab server was allowed by the RExLab group which provided us exclusive access to the experiment.

\section{Evaluation}

The game was evaluated by students from a Brazilian public school. In total, 51 students from the Technical High School of Limeira (COTIL) have participated in activities involving the game. COTIL offers conventional high school education as well as technical education in Construction, Nursing, Cartography and Geodesy, Information Technology, Mechanics, and Quality Management [26].

The average age of the participants was 16 years old, and the majority being male. The game activity was also applied to students from the other two schools, one in Brazil and one in Spain. However, the activity was not fully completed by those students due to technical problems and language issues and, therefore, was not considered here.

The students were divided into two groups: the group $A$ played the digital game integrated with the remote experiment whereas the group $B$ (control group) used the remote experiment directly via the RELLE platform without the game. The activity was performed in two classes of senior-year for two days in a computer laboratory with 20 computers available (one per two students).

We used four questionnaires to collect information from the students: (1) a questionnaire about demographic and technological aspects, (2) a conceptual/procedural questionnaire applied before (pre-test) and after (post-test) using the game and the remote lab, (3) a questionnaire about the experience of using the digital game, and (4) a questionnaire about the experience of using the remote lab. The first questionnaire involved questions about the students' habits of using technologies in order to determine how natural is the interaction with computer technologies. The conceptual/procedural questionnaire has five questions about the photovoltaic effect, for instance, true or false statements like "The light can propagate in different environments?". Both pre- and post-tests have the same content but with different writing.

In order to evaluate the digital game and the remote lab within the experience questionnaire, we used an adapted version of the Model for the Evaluation of Educational Games (MEEGA+) [27]. This model considers usability and user experience as quality factors. These factors were divided into the following dimensions: learning perception, motivation, confidence, challenge, and aesthetics. The MEEGA+ questionnaire was composed of statements and the answers were indicated on a Likert scale which presents the student's level of agreement or disagreement, where -2 means strongly disagree and 2 strongly agree.

The questions were grouped into questions related to the usability, to the learning perception, and to the integration of the game with the remote lab. Nine (group A)/seven (group B) questions were organized to 
determine the quality of the interface, the fonts, the controls, and the management. Seven questions were used to check the learning perception from the student's point of view after using the technologies. The questions include how the technologies contribute to remember concepts and if they are appropriate and efficient to learn the contents. Four questions were dedicated to determining how well the integration with the remote lab occurred (operability), the students' perception during manipulation of the remote experiment (manipulation), the need for integration with a remote experiment (integration need), and the preference of accessing the remote experiment without being integrated into the digital game (without integration).

The activities were conducted by one of the authors (C.N.T) in the presence and with the support of the responsible teacher of the class and took, on average, 50 minutes. Once the students were in the class, the teacher briefly explained the activity and asked the students to fulfill the demographic/technological questionnaire. Then, the students were asked to answer the pretest. After playing with the game (group A) and with the remote lab (group B), the students answered the post-test and the MEEGA+ questionnaire. The ethical aspects of this research were analyzed and approved by the Ethics Committee of the Faculty of the Medical Sciences/University of Campinas (CAAE No. 797320 17.5. 0000.5404).

\section{Results}

Our main goal in this Section is to present the students' evaluation regarding the use and perception of learning from the game combined with the remote experiment. We begin by presenting a profile of the students who participated in the entire process.

\subsection{Technological profile}

Most of the students of this study indicated the habit of using communication technologies with smartphones, accessing the internet mainly from home (Fig. 4). Most of them usually spend 4 to 8 hours per day using these technologies with an average time of $4: 42 \mathrm{~h}$. This value is lower than the average time spent on the internet worldwide of $6: 43 \mathrm{~h}$ by users from 16 to 64 years old and also lower than the average time in Brazil of 9:17 h per day, the third-largest value globally, accordingly to the 2020 Digital Global Overview [28]. However, it is enough time to consider the students very familiar with the communication technologies. Accessing social media, playing games, and studying are the main activities when the students are online, playing games occurring daily.

\subsection{Usability}

The overall perception of the students that played the game (group A) is positive (Fig. 5). The students approved the graphical design, the text fonts, and they enjoy playing the game. In contrast, students that used only the remote lab (group B) remained neutral about usability (Fig. 5).

Students' suggestions and comments about the experience were related to technical aspects of the interface, to the clarity of the purpose of the game with the physical concepts, and to improvements. Among the mentioned improvements are adding control bugs, quicker menu type buttons, more difficult and challenging levels, more support information, and tips to solve the challenges.

\subsection{Learning perception}

Most of the students of group B remained neutral about the learning gain using the remote lab. On the
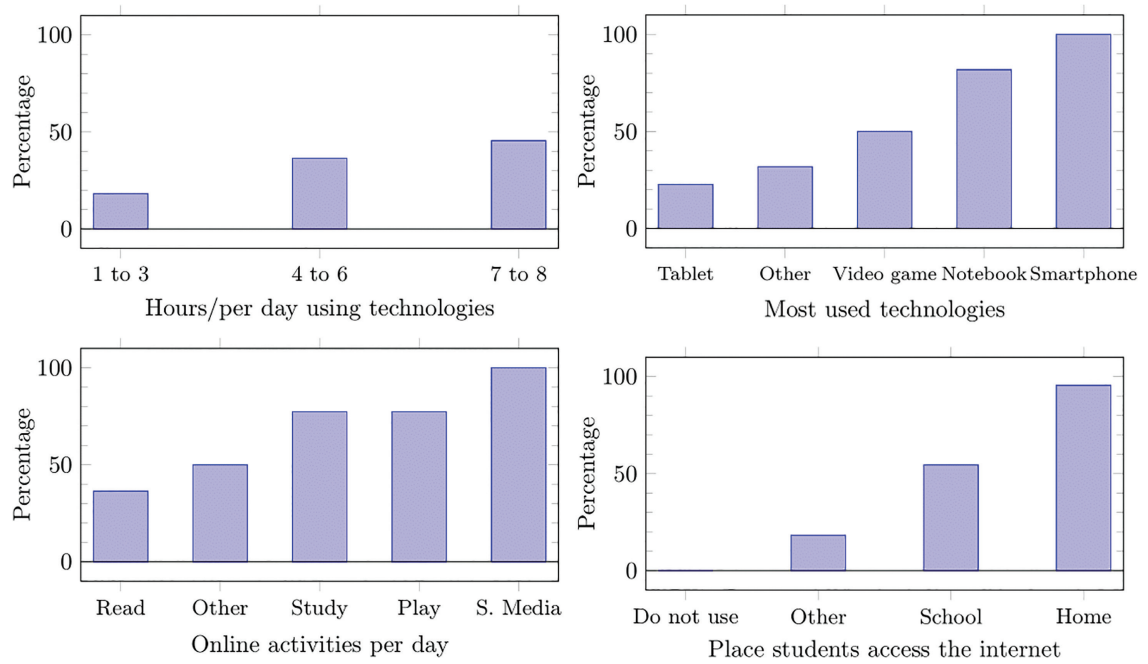

Figure 4: Technological profile regarding the use of internet, preferable access location and devices, and activities. Except for the question about the time spent using technologies, multiple answers were allowed. 


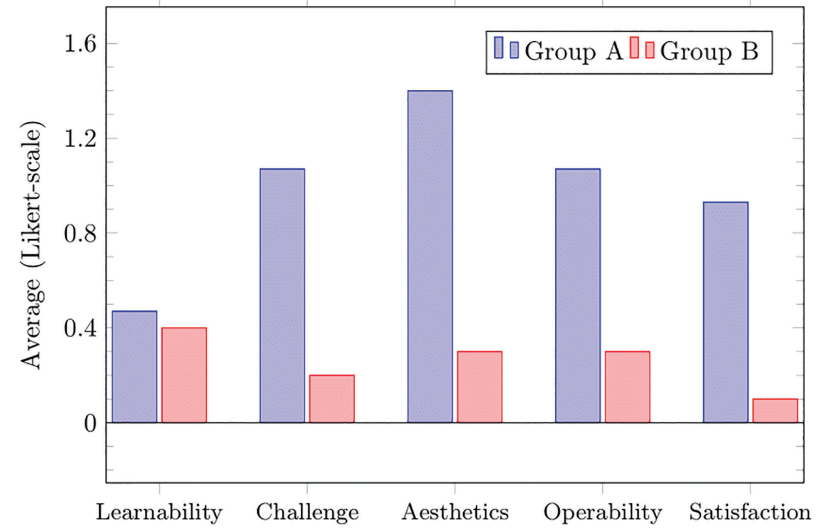

Figure 5: Usability perception.

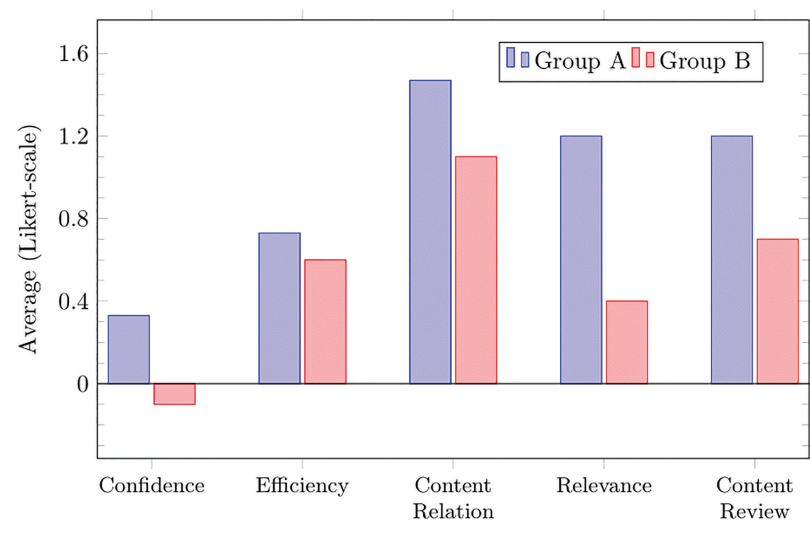

Figure 6: Learning Perception.

other hand, the students of group A agree that the game contents are relevant and that helped them to improve their knowledge and to remember the concepts of the photovoltaic effect (Fig. 6). Despite this learning perception, the students also pointed out the game did not make them more confident about the concepts. Furthermore, we have also observed similar results of the pre- and post-test regarding the photovoltaic effect. This similarity may be explained by the fact the students have already had a class about the photovoltaic effect and the game activity worked as a review of the concept. However, we have observed during the activities that the game encouraged collaborative work.

\subsection{Integration process}

The integration of the remote lab through the game was considered relatively positive (Fig. 7). The students agree that the game facilitated the manipulation of the remote experiment but remained neutral about the operability and the need for integration. The neutral perception of the need for integrating the experiment in a game may be because most of the students have never used a remote lab. To access the remote experiment using the game was preferable rather than to access the experiment directly.

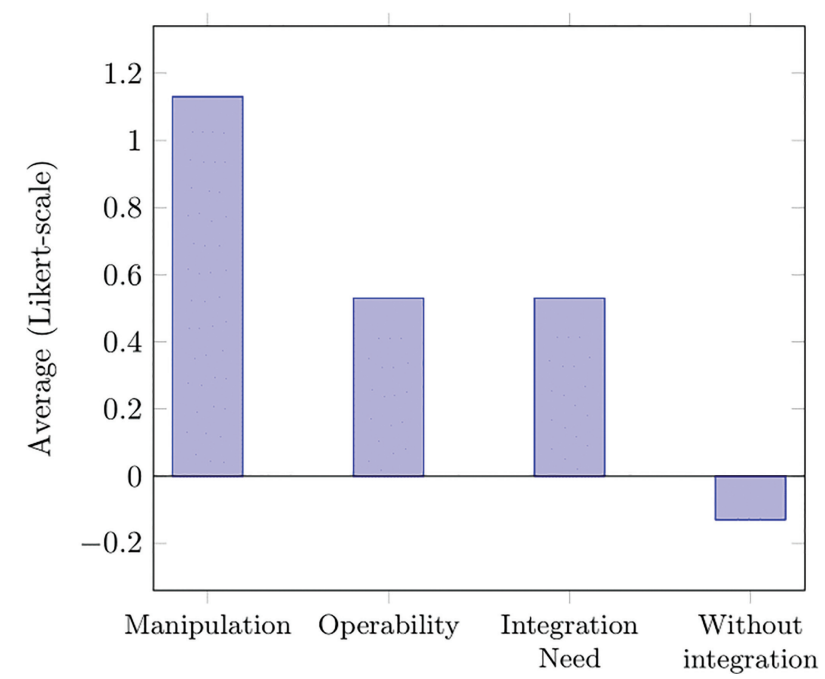

Figure 7: Perception of the integration process.

The group that used directly the online platform of the remote lab had no problems in using the experiment, despite the most of the students pointed out the queuing time and the experiment interface as drawbacks of the platform.

\section{Conclusions}

In summary, we integrated a remote experiment with a digital escape game by using real-time manipulation and visualization from webcam streaming. Applied to teenagers from a Brazilian technical school, questionnaires based on the MEEGA+ model pointed out a positive experience of using the game. Facilitated use of the remote experiment, motivation to learn, collaborative work, and recalling of key concepts were the main benefits obtained with the game with real-time visualization of the remote experiment. Availability of the remote lab and planned activities to reduce queuing time should be considered in the use of motivational, easy access, learning effective, digital games integrated to remote labs.

We believe the principal difference of Fotovolt and other researches is the gamification method. In Fotovolt the user see the remote experiment from the webcam stream and manipulated through the game. The evaluation model used in the validation of Fotovolt is based on questionnaires with Likert scale, a consolidated method found in others researches. As future work we intend to make Fotovolt available on different platforms and operational system.

\section{Acknowledgments}

We acknowledge the São Paulo Research Foundation (FAPESP - Process 2017/13805-8) and Improvement of Higher Education Personnel (CAPES/Brazil). We also 
thank the technical support of the Remote Experimentation Lab (RExLab) and of the Technical High School of Limeira/UNICAMP.

\section{References}

[1] J. Garcia-Zubia, D. López-de Ipiña and P. Orduña, International Journal of Online Engineering 1, 22 (2005).

[2] L. De la Torre, J.P. Sánchez and S. Dormido, Physics Today 69, 48 (2016).

[3] J.B. Silva, The use of remote experimentation as a support to collaborative learning environment. Doctoral Thesis, Universidade Federal de Santa Catarina, Florianópolis (2007).

[4] L.S. Post, P. Guo, N. Saab and W. Admiraal, Computers \& Education 140, 103596 (2019).

[5] M. Prensky, Computers in Entertainment(CIE) 1, 21 (2003).

[6] F. Luthon, A. Petre, D. Steriu and A. Besleaga, in: 3rd International Conference on Signals, Circuits and Systems (SCS) (Medenine, 2009).

[7] O. Dziabenko and J. Garcia-Zubia, in: Global Engineering Education Conference (EDUCON) (Amman, 2011), p. 1102 .

[8] J. Cano, R. Hernandez, S. Ros and L. Tobarra, in: 13th International Conference on Remote Engineering and Virtual Instrumentation (IEEE, Madrid, 2016) p. 183.

[9] L. Rodriguez-Gil, J. Garcia-Zubia and P. Orduña, in: 13th International Conference on Remote Engineering and Virtual Instrumentation (Madrid, 2016) p. 202.

[10] I.A. Zualkernan, G.G. Al Husaini, K.F. Loughlin, J.G. Mohebzada and M. El Gaml, in: 12th International Conference on Advanced Learning Technologies (Rome, 2012) p. 716.

[11] I.A. Zualkernan, G.A. Husseini, K.F. Loughlin, J.G. Mohebzada and M. El Gaml, Chemical Engineering Education 47, 179 (2013).

[12] F. Luthon and B. Larroque, in: 4th Int. Conference on Electronics, Communications and Networks (Beijing, 2014).

[13] F. Luthon and B. Larroque, IEEE Transactions on learning technologies 8, 311 (2015).

[14] M. Hoffmann, L. Plumanns, L. Lenz, K. Schuster, T. Meisen and S. Jeschke, in: Engineering Education 4.0 (Cham, 2016), p. 267.

[15] M.J. Callaghan, K. McCusker, J.L. Losada, J. Harkin and S. Wilson, IEEE Transactions on Industrial Informatics 9, 575 (2013).

[16] C.P. Antonio, J.P.C. Lima, J.B.M. Alves, R. Marcelino, J.B. Silva and J.P.S. Simão, in: 3rd Experiment International Conference (Ponta Delgada, 2015) p. 65.

[17] C.P. Antonio, J. Lima, J.B.M. Alves, J.B. Silva and J. Simão, International Journal of Online Engineering 12, 27 (2016).

[18] C. Antonio, 3D virtual worlds integrated with remote experimentation: application in science teaching. Doctoral Thesis, Universidade Federal de Santa Catarina, Florianópolis (2016).
[19] M.C. Brito and J.A. Silva, Energia fotovoltaica: conversão de energia solarem electricidade, disponível em: http://solar.fc.ul.pt/i1.pdf

[20] Brazilian National High School Education Guideline, disponível em: http://portal.mec.gov.br/docman/jul ho-2013-pdf/13677-diretrizes-educacao-basica-2013-pd $\mathrm{f} /$ file

[21] RELLE, disponível em: http://relle.ufsc.br/labs/10.

[22] Unity 3D, disponível em: https://unity3d.com/

[23] Adobe Photoshop, disponível em: https://www.adobe. com/br/products/photoshop.html

[24] GitHub Fotovolt, disponível em: https://github.com/c arinnant/fotovolt

[25] Websocket, disponível em: https://tools.ietf.org/html/ rfc6455.

[26] COTIL, disponível em: http://www.internationaloffice. unicamp.br/english/wp-content/uploads/2015/07/CO TIL.pdf.

[27] G. Petri, C.G. von Wangenheim, A.F. Borgatto, Technical Report MEEGA+: A Method for the Evaluation of Educational Games for Computing Education INCoD/GQS.05.2018.E, Universidade Federal de Santa Catarina, Florianópolis (2018).

[28] 2020 Digital Global Overview, disponível em: https:// wearesocial.com/blog/2020/01/digital-2020-3-8-billionpeople-use-social-media. 